\title{
Investigation of the Fracture Mechanics Properties of Small Tubes from Oxide Dispersion Strengthened Steels
}

\author{
ALEXANDRU NITU', MARIOARA ABRUDEANU2,2*, VASILE RADU ${ }^{1}$ \\ ${ }^{1}$ Institute for Nuclear Research Pitesti, 1 Campului Str., 115400, Mioveni, Arges, Romania \\ 2 University of Pitesti, 1 Targul din Vale Str., 110040, Pitesti, Arges, Romania \\ ${ }^{3}$ Technical Science Academy of Romania, 26 Dacia Blvd., Bucharest, Romania
}

The paper presents one partfrom the RATEN ICN contribution to the European FP7 MatISSE Project objectives, which is focused on the fracture mechanics properties of small tubes made from ODS steels (Oxide Dispersion Strengthened steels). The ODS tubes are foreseen as cladding tubes for gen IV reactors, and therefore the mechanical properties are very important for working in the most aggressive environment (irradiation and high temperatures) during the gen IV reactor operation. The fracture toughness, $K_{1,}$, could be obtained for tubes with small diameters by means of the PLT-type mechanical test (acronym for PinLoading Test). This kind of test is a non-standard (ASTM) mechanical test, and during last decade it is still worldwide under development. The specific specimens for PLT-tests has been prepared from ODS tubes, which were provided to the project by the CEA France, a partner in the FP 7 MatISSE, in two different compositions: Fe-9cr ODS and Fe-14 Cr ODS. The paper highlights the PLT experimental test methodology, starting with obtaining of the geometric function, description of the experimental set-up and results processing.

Keywords: Pin-Loading Test, ODS steels, $K_{1 C}$ parameter, geometric function

Thin-walled tubes with small diameter are used on a large scale in nuclear power plants. More often, these tubes are used as heat exchanger tubes, steam generator tubes and nuclear cladding tubes [1]. The operating conditions of these tubes are severe due to high temperatures and mechanical stresses combined with the effects of radiation on the material properties [2]. The cracking behavior of thin-walled tubes is an important feature for the structural integrity assessment during operation.

Given these considerations, to ensure the structural integrity of components which are on use in nuclear installations, it was necessary to know their resistance to the initiation and propagation of crack (fracture toughness). Because of their dimensions, it is not possible to prepare the standard fracture mechanics specimens for the classical ASTM tests. Therefore it is need to introduce the new methods for assessing the fracture material properties of tubes with thin walls [3]. One of these has been introduced by Grigoriev [4,5], and is called Pin-Loading Test (PLT), that is described in the next.

\section{Experimental part}

Fracture mechanics parameter, $\mathrm{K}_{1}$, could be obtained by means of the Pin-Loading Test, and this method requires the existence of tube sample with a very sharp artificial mechanical defect [6]. In the case of PLT method, the tension is applied at one end of the sample in comparison with an axial tensile test on the same sample type [7-9]. The advantage is that the tension required for the deformation of the sample and the elastic deformation of the gripping system are lower than the uniaxial tensile test. Therefore, the elongation of the sample is bigger and the recorded data is enough to characterize the material in contrast with the uniaxial tensile test, where the elastic deformation of the gripping system has a major influence, especially for materials with low ductility, causing rupture of the sample at extremely small elongation, and the recorded data is insufficient to characterize the material (fig.1) [10-12].

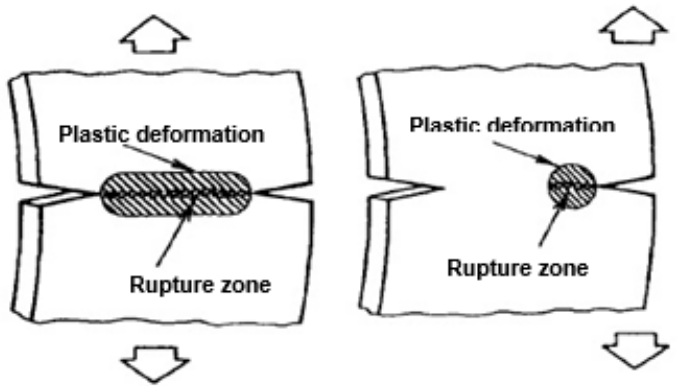

Fig. 1. Sample deformation by: a) uniaxial tensile test,

b) PLT test

The material used for the PLT tests was distributed by CEA France within the framew ork of European FP7 MatISSE Project and consists of ODS steel tubes in two differentcompositions: Fe-9CrODS and Fe-14CrODS. The dimensional characteristics are:

-inner diameter: $9.70 \mathrm{~mm}$

-wall thickness: $0.60 \mathrm{~mm}$;

The PLT type specimens were obtained by machining processes that included cutting, milling and electroerosion. Figure 2 shows the sketch of PLT sample and the figure 3 presents the samples used for testing.

At each end of the sample were performed two diametrically opposed clefts. The clefts from the bottom part of the sample have a depth of $2 \mathrm{~mm}$ and a width of 0.5 $\mathrm{mm}$, and their role is a technological one [13-15]. The clefts

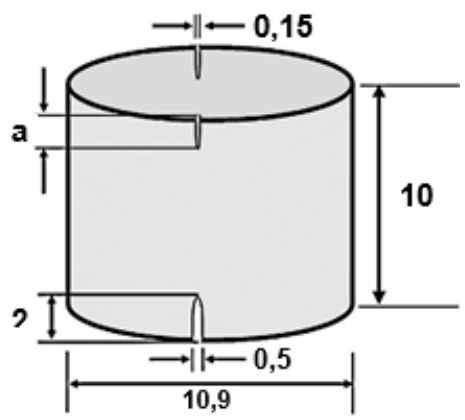

Fig. 2. PLT sample dimensions in $\mathrm{mm}$ (crack length $\mathrm{a}=1.5 \mathrm{~mm} ; 3 \mathrm{~mm}$; $5 \mathrm{~mm})$

*email: abrudeanu@gmail.com; Phone: 0740.504.086 

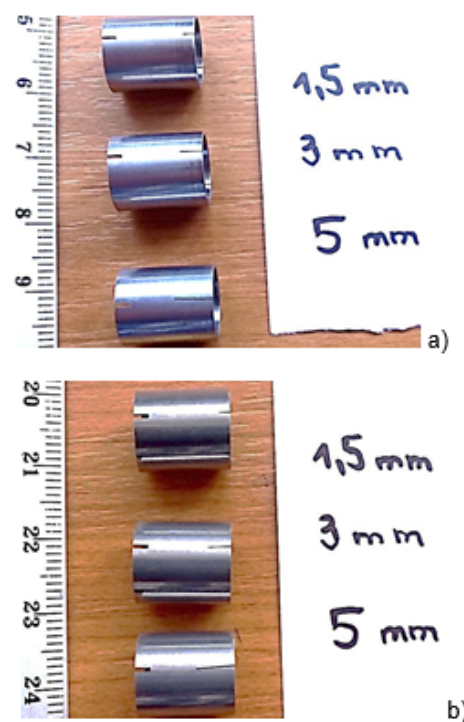

Fig. 3. PLT samples for before testing: a) $\mathrm{Fe}-\mathrm{9Cr}$ ODS; b) Fe-14Cr ODS

b)

\section{Obtaining geometric function}

To determine compliance, three mechanical tests were conducted for each from two kinds of materials. For this it have been used the samples with different lengths of the test clefts (1.5, 3 and $5 \mathrm{~mm}$ ). From the experimental curve, the compliance was calculated for each sample with the equation (2).The results for samples of Fe-9Cr ODS are provided in table 1.

$$
C=\frac{\Delta x}{\Delta P}
$$

Figure 5 shows an example of calculating compliance for Fe-9Cr ODS sample with $3 \mathrm{~mm}$ test cleft length.

\section{Table 1}

DETERMINATION OF COMPLIANCE FOR STEEL Fe-9Cr ODS

\begin{tabular}{|c|c|c|}
\hline Material & $\begin{array}{c}\text { Test cleft } \\
\text { length }(\mathbf{m m})\end{array}$ & $\begin{array}{c}\text { Compliance } \\
\left(10^{-6} \mathbf{m} / \mathbf{N}\right)\end{array}$ \\
\hline \multirow{3}{*}{ Fe-9Cr ODS } & 1.5 & 0.54 \\
\cline { 2 - 3 } & 3 & 0.64 \\
\cline { 2 - 3 } & 5 & 1.14 \\
\hline
\end{tabular}

from the top of the sample are very important because from these clefts the fracture initiate and its propagating until the sample break off. The sizes of these clefts are variable regarding to the depth, from $1.5 \mathrm{~mm}$ to $5 \mathrm{~mm}$. The width is kept constant - about $0.15 \mathrm{~mm}$.

For both compositions have been performed two sets of samples. The first set includes three samples with different lengths of test clefts $(1.5 \mathrm{~mm}, 3 \mathrm{~mm}$ and $5 \mathrm{~mm})$. These samples are used to obtain the specimen compliance. The second set comprises three samples with the same length of test clefts - $1.5 \mathrm{~mm}$ and are used to obtain $\mathrm{K}_{\mathrm{C}}$ from the PLT tests. The results recorded from the PLT tests are used to calculate the fracture toughness, $\mathrm{K}_{1,}$ of the material.

The following relationship is used to obtain $\mathrm{K}_{\mathrm{IC}}$ :

$$
K_{I C}=\left[\frac{P_{Q}}{2 t \sqrt{W}}\right] \cdot f\left(\frac{a}{W}\right)
$$

Here:

$w=$ distance between the load application point and the technological crack tip (fig.4)

$t=$ wall thickness of the tube;

$P_{0}=$ applied load;

$f(a / W)=$ geometric function

One may see, that the fracture toughness determination is subject to the determination of the applied load $P_{0}$ and geometric function $f(a / W)$. Geometric function is obtained from measurements of compliance.
$C_{3}=\frac{\Delta x}{\Delta P}=\frac{0,48 \mathrm{~mm}}{750 \mathrm{~N}}=0,64 \cdot 10^{-3} \frac{\mathrm{mm}}{\mathrm{N}}=0,64 \cdot 10^{-6} \frac{\mathrm{m}}{\mathrm{N}}$

In order to perform curve fitting the following points for are chosen:

$$
\left[\frac{a}{W}\right]=\left[\frac{a_{1}}{W}, \frac{a_{2}}{W}, \frac{a_{s}}{W}\right]
$$

where:

$$
\begin{aligned}
& \left\{\begin{array} { l } 
{ a _ { 1 } = a _ { 0 1 } + b } \\
{ a _ { 2 } - a _ { 0 2 } + b } \\
{ a _ { 3 } - a _ { 0 3 } + b }
\end{array} \text { but } \left\{\begin{array}{l}
a_{01}=1,5 \mathrm{~mm} \\
a_{02} \\
a_{30}-5 \mathrm{mmm}
\end{array}\right.\right. \\
& \text { and } b=7,5 \mathrm{~mm} \Rightarrow\left\{\begin{array}{c}
a_{1}=9 \mathrm{~mm} \\
a_{2}=10,5 \mathrm{~mm} \\
a_{3}=12,5 \mathrm{~mm}
\end{array}\right.
\end{aligned}
$$

With relation (5) and $W=18.5 \mathrm{~mm}$, the relation (4) becomes:

$$
\left[\frac{a}{W}\right]=\left[\frac{9}{18,5}, \frac{10,5}{18,5}, \frac{12,5}{18,5}\right]=[0,4865 ; 0,5675 ; 0,6757]
$$

In a first step an exponential fitting is performed on compliance parameters $[\mathrm{C}]=[\mathrm{C} 1,5, \mathrm{C} 3, \mathrm{C} 5]=[0.54 ; 0.64$; $1.14]$ and $[\mathrm{a} / \mathrm{W}]=[0.4865 ; 0.5675 ; 0.6757]$. In a second step a 6th order polynomial fitting is performed on the output of the exponential fitting and the result is the following compliance relationships:

$$
C\left(\frac{a}{w}\right)=10^{-5}\left[0.3105 \cdot\left(\frac{a}{w}\right)^{6}-0.2238 \cdot\left(\frac{a}{w}\right)^{5}+0.6729 \cdot\left(\frac{a}{w}\right)^{4}+0.3671 \cdot\left(\frac{a}{w}\right)^{3}+0.6174 \cdot\left(\frac{a}{w}\right)^{2}+0.4357 \cdot\left(\frac{a}{w}\right)+0.1663\right]
$$

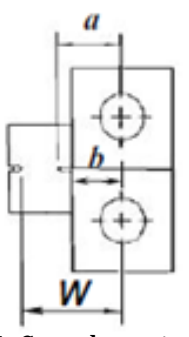

Fig. 4. Sample - gripping system assembly

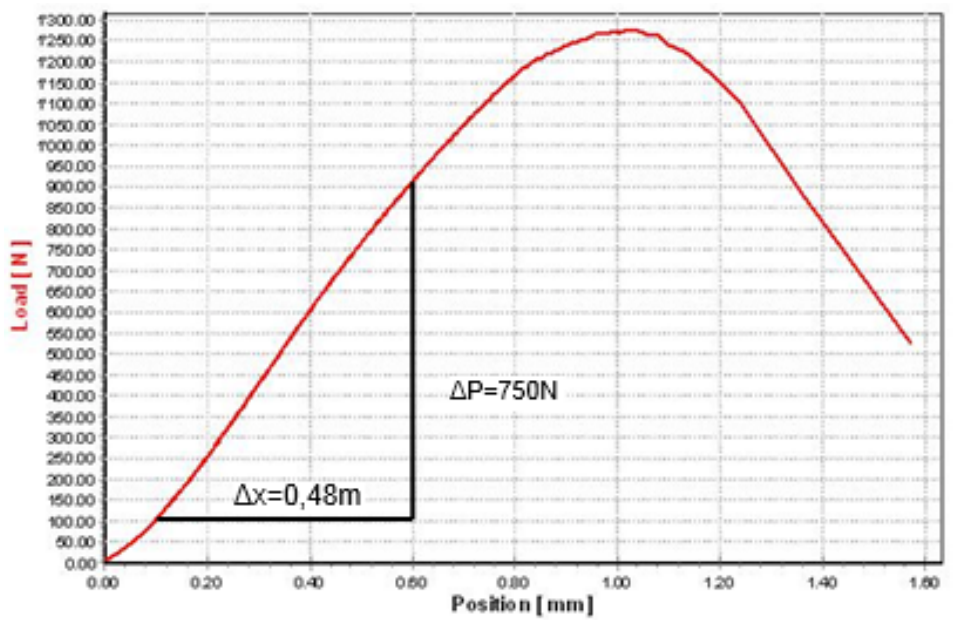

Fig. 5. Determination of compliance for Fe-9Cr ODS specimen with $3 \mathrm{~mm}$ test cleft length 

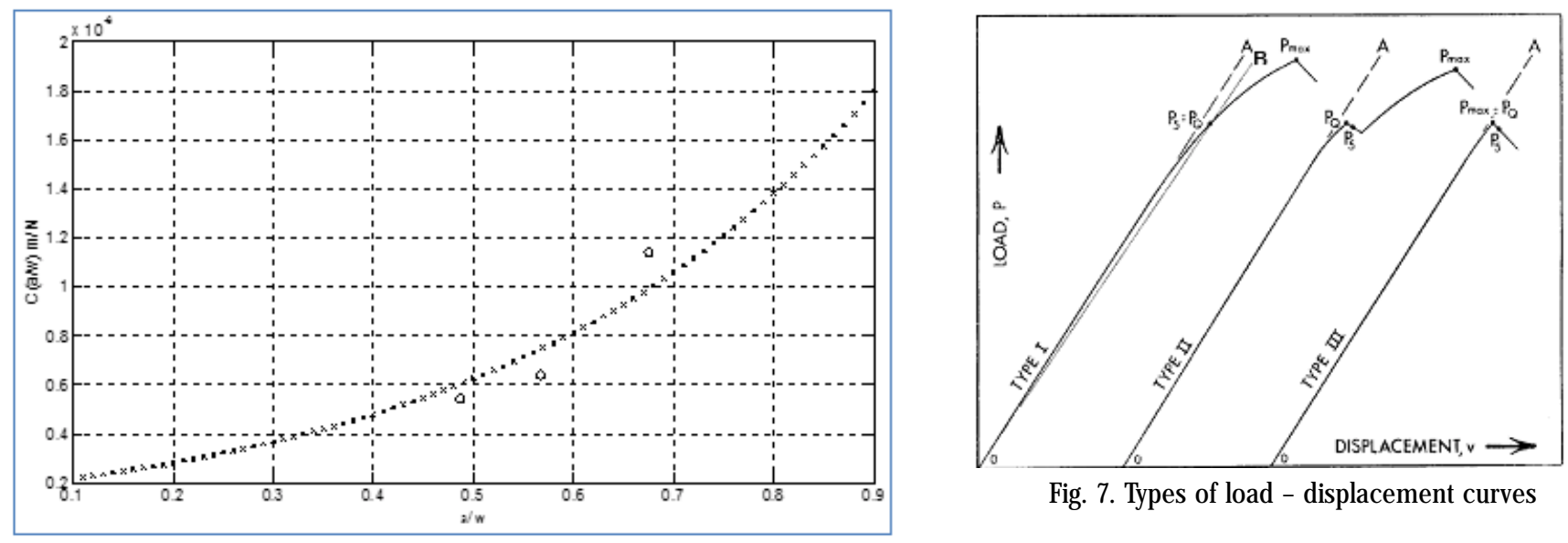

Fig. 7. Types of load - displacement curves

Fig. 6. Polynomial fitting of compliance forFe-9Cr ODS

Further on the derived compliance is calculated and the relation is:

$$
\frac{d C}{d(a / w)}=f_{2}\left(\frac{a}{w}\right)=10^{-6} \cdot\left[1.863 \cdot\left(\frac{a}{w}\right)^{5}-1.119 \cdot\left(\frac{a}{w}\right)^{4}+26916 \cdot\left(\frac{a}{w}\right)^{3}+1.1013 \cdot\left(\frac{a}{w}\right)^{2}+1.2348 \cdot\left(\frac{a}{w}\right)+0.4357\right]
$$

Thus, the geomeu ic iuricuurı is yivelı ny uie ielauviı:

$$
f\left(\frac{a}{W}\right)=\left[t \cdot E \cdot f_{2}\left(\frac{a}{W}\right)\right]^{\frac{1}{2}}
$$

Here:

$\mathrm{t}=0.6 \mathrm{~mm}$;

$\mathrm{E}=200 \mathrm{GPa}$ - Young modulus [16].

By putting equation (8) into equation (9) the final form of the geometric function for Fe-9Cr ODS specimen is:

$$
f\left(\frac{a}{w}\right)=0.7946 \cdot\left(\frac{a}{w}\right)^{5}-0.2936 \cdot\left(\frac{a}{w}\right)^{4}+4.0012 \cdot\left(\frac{a}{w}\right)^{3}+5.8040 \cdot\left(\frac{a}{w}\right)^{2}+9.7427 \cdot\left(\frac{a}{w}\right)+7.2554
$$

The fracture toughness $K_{\text {IC }}$ from PLT (11):

The fracture toughness could be obtained with equation

$$
K_{I C}=\left[\frac{P_{Q}}{2 t \sqrt{W}}\right] \cdot f\left(\frac{a}{W}\right),
$$

and here the values of the factors $a, t$ and $w$ are known. Moreover, the $P_{0}$ load values are obtained by analyzing experimental curves for the PLT tests as recommended by ASTM (fig.7) [17-19].

The steps are the following:

-By origin, goes on a secant $\mathrm{OA}$ which is tangent to the elastic deformation zone;

-Another secant $O B$ determines the formation of an origin angle which is representing $95 \%$ of $\mathrm{OA}$ origin angle;

-The intersection between these two secants and the experimental curve determines the corresponding point for the $P_{5}$ load [20].

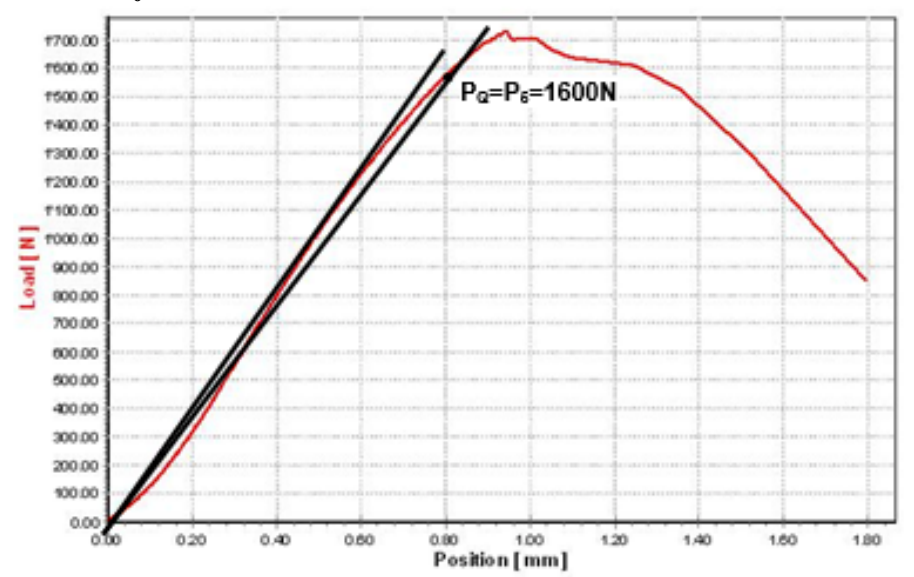

Fig. 8. $\mathrm{P}_{\mathrm{Q}}$ load determination for "Fe-9Cr ODS - test1" sample
There are two typical situations for the determination of $P_{Q}:$

-If the points on the experimental curve which are preceding the $P_{5}$ point, have lower load values than the value corresponding to $P_{5}$ point it is considered that $P_{5}=P_{0}$ (type I in fig. 7);

-If there is a point on the experimental curve graph preceding $\mathrm{P}_{5}$ point where for the value of the load is higher than the load value for $P_{5}$ point, then that point will be $P_{Q}$ (type II and III in fig. 7).

Figure 8 shows how the $P_{0}$ was determinate by using the tensile test curve from current test.

\section{Results and discussions}

Three samples were tested to obtain $\mathrm{P}_{0}$ values, and these values were introduced in equation (11) to obtain the $\mathrm{K}_{\text {IC }}$ values of fracture toughness. The results for $\mathrm{Fe}-\mathrm{gCr}$ ODS are shown in table 2.

Table 2

VALUES of $\mathrm{K}_{\mathrm{IC}}$ FOR Fe-9Cr ODS STEEL

\begin{tabular}{|c|c|c|}
\hline Sample cod & $P_{Q}(\mathrm{~N})$ & KIC $\left._{\text {(MPa.m }}{ }^{\mathrm{Iz}}\right)$ \\
\hline Fe-9Cr_test 1 & 1600 & 135.6 \\
\hline Fe-9Cr_test 2 & 1710 & 144.9 \\
\hline Fe-9Cr_test 3 & 1610 & 136.5 \\
\hline
\end{tabular}

Table 3

VALUES OF $K_{1 C}$ FOR Fe-14Cr ODS STEEL

\begin{tabular}{|c|c|c|}
\hline Sample cod & $P_{Q}(\mathrm{~N})$ & KIC $\left(\mathbf{M P a m}^{1 / 2}\right)$ \\
\hline Fe-14Cr_test1 & 1333 & 122.2 \\
\hline Fe-14Cr_test2 & 1330 & 121.9 \\
\hline Fe-14Cr_test3 & 1336 & 122.5 \\
\hline
\end{tabular}


The mean value of the toughness $\mathrm{K}_{1 \mathrm{t}}$ that was obtained from our tests is of $139 \mathrm{MPa} \cdot \mathrm{m}^{1 / 2}$. This value is in a good agreement with the mentions from MatISSE Plenary Meeting in 2017, where it was concluded that the $K_{\text {If }}$ values must be found within the range of $80-180 \mathrm{MPa} \cdot \mathrm{m}^{\mathrm{Lf} / 2}$.

A similar methodology has been used to obtain the fracture toughness values for Fe-14Cr ODS samples and table 3 presents the results.

One may see that for the Fe-14Cr ODS steel, the average value of the fracture toughness obtained by testing (122 $\left.\mathrm{MPa} . \mathrm{m}^{1 / 2}\right)$ is also in good agreement with the remarks from the MatISSE Project (80-180 MPa.m ${ }^{1 / 2}$ ).

\section{Conclusions}

This paper outlines the non-standard test methodology to obtain the fracture toughness for ODS tubes with small diameter, and the results could be used in the structural analyses for cladding tubes in gen IV reactors. The paper highlights the Pin-Loading Test (PLT) experimental test methodology, description of the geometric function obtaining and the results processing as well, in order to obtain the fracture toughness for ODS tubes.

A part of the work has been performed inside of the contribution of RATEN ICN in the framework of activities conducted in the European FP7 Matisse Project (20142017). The mean values obtained in the paper work for $\mathrm{K}_{\mathrm{c}}$ are: $139 \mathrm{MPa} . \mathrm{m}^{1 / 2}$ for Fe-9Cr ODS and $122 \mathrm{MPa} \cdot \mathrm{m}^{1 / 2}$ for Fe$14 C r$ ODS. These values are in a good agreement with the range values mentioned by the MatISSE project participants $\left(80-180 \mathrm{MPa}^{1 / 2}\right)$.

The non-standard PLT testing methodology is under development and improvement, in order to be applied to other candidate structural materials used in generation IV reactors.

Acknowledgment: This work was accomplished thanks to the financial support from the European Commission, in the framework of the MatISSE project under Grant No. 604862 and contributes to the Joint Programme on Nuclear Materials (JPNM) of the European Energy Research Alliance (EERA). We also express our gratitude to the CEA France partners, for providing the ODS tube samples and some material information.

\section{References}

1. M. K. SAMAL et. all, A load-separation technique to evaluate crack growth and fracture resistance behaviour of thin-walled axially cracked tubular specimens, Proc. IMechE Vol. 226 Part C: J. Mechanical Engineering Science;

2. *** Handbook of Generation IV Nuclear Reactors, Elsevier, 2016 ch 6, Lead coled fast reactors.

3. G. SANYALET. ALL, PREDICTION OF J-R curves of thin-walled fuel pin specimens in a PLT setup, Engineering Fracture Mechanics 78 (2011) 1029-1043;

4. V. GRIGORIEVET. all, A pin-loading tension test for evaluation of thin-walled tubular materials, Scripta Metallurgica et Materialia, Vol. 33, No. 1, pp. 109-114, 1995;

5.GRIGORIEV ET. all, Application of the Pin-Loading Tension Test to Measurements of Delayed Hydride Cracking Velocity in Zircaloy Cladding, SKI Report 00:57, November 2000;

6. SETOYAMA D., YAMANAKA S., J. Alloys Compd., 370, no. 1-2, 2004, p. 144-148.

7. COX B., J. Nucl. Mater., 336, Issues 2-3, 2005, p. 331.

8. DINU A., ABRUDEANU M., Rev. Chim.(Bucharest), no. 8, 2007, p.751. 9. ARCHAMBAULT P., ABRUDEANU M., COLLERET B., J. Nucl. Mater, 200, Issue 2, 1993, p. 162.

10.DUMITRESCU, I.M., MIHALACHE, M., ABRUDEANU, M., Rev. Chim.(Bucharest), 66, no. 2, 2015, p. 290.

11.DUMITRESCU, I., MIHALACHE, M., DINU, A., MELEG, T., OHAI, D., ABRUDEANU, M., Rev. Chim.(Bucharest), 66, no. 3, 2015, p. 316.

12.ABRUDEANU M., ARCHAMBAULT P., 9e Congres International du Traitement Thermique et de I'Ingénierie des Surfaces, Nice, 1994, p. 87.

13.ABRUDEANU M., ARCHAMBAULT P., Conference Zr-95, Saclay, France, 1995, p. 303.

14.ABRUDEANU M., ARCHAMBAULT P., PETOT-ERVAS G, PETRESCU N., PETRESCU M., Proceeding of the Second International Conference Held at Selwyn College University of Cambridge, IM- ISBN 0901716502 , 1993, p. 387.

15.ABRUDEANU M., PETRESCU N., International Conference of Diffusion and Defects in Solids DD91, Academy of Sciences, MoscouURSS, 75, 1991, p. 84.

16. YAN DE CARLAN, CEA, Privat communication;

17. *** ASTM E399, Standard testmethod for plane-strain fracture toughness of metallic materials.

18. LECLERCQ B., These de doctorat Universite de Limoge, 2002.

19. LAURENT M., VUILLERMOZ P.-L., Conductivite thermique des solides, Techniques de I'Ingenieur, 1993.

20. SWAIN M.V., J OHNSON L.F., SYED R., HASSELMAN D.P.H., J . Mater. Sci. Lett., 5, 1986, p. 799.

$\overline{\text { Manuscript received: } 14.06 .2018}$ 